\title{
Navigating the Diagnostics of COVID-19
}

\author{
Adekunle Sanyaolu ${ }^{1,2}$ (D) Chuku Okorie ${ }^{3}$. Aleksandra Marinkovic ${ }^{4} \cdot$ Oladapo Ayodele $^{4} \cdot$ Abu Fahad Abbasi $^{4}$. \\ Stephanie Prakash ${ }^{4} \cdot$ Miriam Ahmed $^{4} \cdot$ Damilare Kayode $^{2} \cdot$ Urooj Jaferi $^{5} \cdot$ Nafees Haider $^{5}$
}

Accepted: 10 July 2020 / Published online: 25 July 2020

(C) Springer Nature Switzerland AG 2020

\begin{abstract}
The recent outbreak of the severe acute respiratory syndrome coronavirus 2 (SARS-CoV-2) began in Hubei province, China, in December 2019 and has spread worldwide at an alarming rate. With over eight million individuals infected and exceeding 400,000 deaths globally, the necessity to develop fast and efficient diagnostic methods is of high importance. This paper reports on currently available diagnostic screening methods for patients infected with SARS-CoV-2 to guide frontline healthcare workers involved with the diagnosis of 2019 novel coronavirus disease (COVID-19) patient. An electronic literature search was performed for peer-reviewed articles published from January 1, 2020, until June 19, 2020. Published articles were then reviewed and included based on the applicability to the topic. The preferred diagnostic approach is the reverse transcription (RT) of the virus' ribonucleic acid (RNA) followed by polymerase chain reaction (PCR) amplification (RT-PCR). However, this method has been proven to be time-consuming. In improving the speed and efficiency of diagnostics, newer rapid diagnostic serological tests are in development for testing SARS-CoV-2, each with its unique advantages and disadvantages. They could potentially be used as triage tests to rapidly identify patients who are very likely to have COVID-19 in combination with other accurate diagnostic methods, such as diagnostic imaging. A combination of the disease history, clinical manifestations, laboratory diagnostic testing, and diagnostic imaging is crucial for making an accurate and useful diagnosis for COVID-19. Hopefully, the continuous development and use of rapid diagnostic tests and the implementation of public health measures will help control the spread of the disease.
\end{abstract}

Keywords COVID-19 $\cdot$ SARS-CoV-2 $\cdot$ RT-PCR $\cdot$ Diagnostic test $\cdot$ Serology

\section{Introduction}

The coronavirus disease 2019 (COVID-19) started in Hubei province, China, and is caused by severe acute respiratory syndrome coronavirus 2 (SARS-CoV-2) [1]. The virus was named 1 week after China alerted the World Health Organization (WHO) that it has identified a cluster of cases of pneumonia of unknown origin [2]. Reported symptoms

This article is part of the Topical Collection on Covid-19

Adekunle Sanyaolu

sanyakunle@hotmail.com

Federal Ministry of Health, Abuja, Nigeria

College of Medicine of the University of Lagos, Lagos, Nigeria

Essex County College, Newark, NJ, USA

4 Saint James School of Medicine, Anguilla, BWI, UK

5 All Saints University School of Medicine, Roseau, Dominica include fever, cough, fatigue, pneumonia, headache, diarrhea, hemoptysis, and dyspnea [1,3]. Based on symptoms and early radiographic evidence, COVID-19 was initially thought to be influenza or the common cold. When further tests failed to identify the pathogen, bronchoalveolar lavage (BAL) fluid analysis from the patient's lungs showed the genomic identity of this virus and that it is approximately $80 \%$ like the genome of the SARS coronavirus (SARS-CoV-1) [1]. SARS-CoV-1 was the cause of the severe acute respiratory syndrome outbreak in 2003, which also started in China [1,4].

Coronavirus is an envelope, positive-stranded ribonucleic acid (RNA) virus with a "crown-like" spike on its surface [4]. The virus belongs to the subfamily Orthocoronavirinae and like SARS coronavirus, SARS-CoV-2 falls into the genus betacoronavirus and subgroup sarbecovirus [4]. As a respiratory virus, the efficiency of its transmission has made SARSCoV-2 difficult to contain and evidence indicates that it spreads through droplets and direct contact [1]. Also, van Doremalen and colleagues showed that the virus could be stable for at least 3 hours in aerosols [5]. 
Researchers have identified and reported that SARS-CoV2 utilizes the angiotensin-converting enzyme 2 (ACE2) as a receptor to enter and infect cells $[1,3,4]$. This is not surprising as this was also observed during the SARS coronavirus outbreak in 2003 [4]. Furthermore, since SARS-CoV-2 is a zoonotic disease that most likely originated in bats, there is the possibility that SARS-CoV-2 adapted to a non-bat ACE2 variant, increasing its ability to affect humans [6]. The disease has spread outside of Hubei province and as of June 19, 2020, there are 8,385,440 confirmed COVID-19 cases and 450,686 COVID-19-associated deaths, reported globally [7]. Restricted travel orders have been implemented by several government authorities worldwide, yet community spread continues to increase the incidence and death rate of the disease [8].

Several individuals have been described as asymptomatic spreaders of the disease [8], and in one study, these asymptomatic individuals are identified as super spreaders who in a healthcare setting consisted of $29 \%$ of the healthcare staff and $12.3 \%$ of the 138 admitted patients [9]. Unfortunate events like these have necessitated the implementation of public health measures such as social distancing, isolation, contact tracing, and quarantine, in a bid to mitigate the burden of the disease [8]. However, as COVID-19 surges across the globe, scientists strive to leverage the power of testing and diagnosis of the disease. This review summarizes the diagnostic modalities used to detect, identify, and diagnose COVID-19. We aim to report on the currently available point-of-care diagnostics, as well as those that are on the horizon. This is a rapidly evolving topic of research and we hope that this review provides information for future research studies.

\section{Methodology}

An electronic literature search was performed using PubMed, Google Scholar, EBSCOhost, Mendeley, and MedLine Plus. The search was limited to peer-reviewed articles mostly published from January 1, 2020, until June 19, 2020. An article was selected if it included keywords such as coronavirus, COVID-19, SARS-CoV-2, diagnostics, diagnostic tests, and serology. Articles were then reviewed and included based on the applicability to the topic.

\section{Diagnostic Testing Measures}

\section{Clinical Presentation}

Since first emerging as a respiratory illness in December 2019 , the WHO has described the spectrum of the novel COVID-19 ranging from asymptomatic or an acute mild respiratory illness, to a rapidly progressive severe pneumonia complicated by respiratory failure and mortality $[10,11]$. Though research on the full clinical manifestations of COVID-19 is ongoing, the primary presentation reported includes non-specific systemic and/or respiratory symptoms ranging from fever, dry cough (with or without sputum production), fatigue, anorexia, shortness of breath, myalgia, or arthralgia $[11,12]$. Among a cohort of 55,924 confirmed COVID-19 cases across China, fever (87.9\%), dry cough $(67.7 \%)$, fatigue $(38.1 \%)$, and sputum production $(33.4 \%)$ were the most common clinical features [12]. Additional reported signs and symptoms include headache, confusion, rhinorrhea, conjunctival injection, sore throat, hemoptysis, vomiting, and diarrhea [12]. Anosmia or ageusia preceding the onset of respiratory symptoms has also been anecdotally reported from cases outside of China; however, more information is needed to understand the role of these symptoms in relation to COVID-19 [11, $13,14]$. Several studies have reported disease in children to be relatively rare and/or mild with signs and symptoms of COVID-19 similar to those of adults, although severe illness has also been reported [11, 12].

According to the current epidemiological studies, the incubation period for COVID-19 can extend up to 14 days, with a reported median time of 5 to 6 days from exposure to the development of mild symptoms [11]. However, some can rapidly deteriorate with worsening dyspnea within 5 to 8 days of symptom onset, requiring hospitalization and oxygen support $[11,14]$. In a retrospective cohort study of the 44,672 confirmed COVID-19 cases from China, approximately $81 \%$ were classified as an uncomplicated mild illness, $14 \%$ progressed to severe pneumonia (dyspnea, tachypnea, hypoxic with blood oxygen saturation $\leq 93 \%, \mathrm{PaO} 2 / \mathrm{FiO} 2$ ratio $<300$, and $/$ or $>50 \%$ lung infiltrates on imaging), and $5 \%$ were in critical condition (acute respiratory distress syndrome, septic shock, and/or multiple organ dysfunction/failure) requiring intensive care and/or mechanical ventilation $[10,11,14]$. The study revealed a case fatality rate of $2.3 \%$, with all deaths among patients with critical illness [11].

Preliminary data from China, Italy, and New York City in the United States of America (USA) suggest individuals $\geq$ 65 years of age, immunosuppressed, or those with underlying comorbidities (hypertension, diabetes mellitus, cardiovascular disease, cirrhosis, body mass index $\geq 30$, chronic respiratory disease or cancer) are at higher risk for severe disease and mortality $[15,16]$.

Due to the disease's unpredictable clinical presentation and course, early recognition and diagnosis of individuals suspected of having COVID-19, especially those at increased risk of severe disease, can allow for optimized supportive care including admission to designated hospital wards or intensive care units (ICUs), depending on the clinical state [10]. 


\section{Laboratory Examination}

Reported laboratory findings in confirmed COVID-19 cases include biomarkers representing an inflammatory host response to pathogens and/or early markers of end-organ dysfunction in severe cases [14]. Common abnormalities, although non-specific, include lymphopenia, decreased albumin, elevated C-reactive protein (CRP) and erythrocyte sedimentation rates (ESR), and elevated lactate dehydrogenase (LDH) levels $[11,17]$. Additional biomarkers that may be seen with disease progression include leukocytosis and/or leukopenia, elevated ferritin, elevated aspartate aminotransferase (AST), alanine aminotransferase (ALT), or elevated creatinine kinase (CK) $[11,14]$. Emerging data suggest that infection with SARS-CoV-2 may result in cardiovascular injury and an elevated troponin detected in isolation without clinical or electrocardiographic features of an acute coronary syndrome (ACS) $[16,18]$.

To date, no specific biomarker or combination of biomarkers found on laboratory testing has been reported to be sensitive or specific to establish a diagnosis of COVID-19 or to pragmatically predict its clinical course [17]. However, the WHO recommends hematology and biochemistry laboratory testing (CRP, liver function test, cardiac enzymes, renal function, coagulation factors, blood gas analysis, etc.) including electrocardiogram (ECG), to be performed at hospital admission and as clinically indicated to monitor for complications, such as acute liver injury, acute kidney injury, and acute cardiac injury or shock [10].

\section{Imaging}

In the early stages of confirmed COVID-19 cases, retrospective studies suggest chest radiographs may be unremarkable or can show nonspecific multi-lobar consolidations that can rapidly progress by day 10-12 following symptom onset, to severe pneumonia with bilateral ground-glass opacities, usually in peripheral distribution, depicted in Fig. 1 [19].

In contrast, chest computed tomography (CT) scan findings, though not specific for COVID-19-associated pneumonia, may be more sensitive for diagnosis than chest radiograph, especially where viral testing may be constrained or during a false-negative nasopharyngeal real-time reverse-transcription polymerase chain reaction (RT-PCR) test in mild or severe suspected cases $[11,17,20]$. Retrospective case studies identified diverse abnormal CT findings, including groundglass opacities most prominent from day 0 to day 4 after symptom onset (usually bilateral and peripheral distribution), which can become very extensive with disease progression and present as multifocal solid consolidative opacities [11, 14]. Additional findings reported include vascular thickening, or inter-/intra-lobular septal thickening ("crazy paving appearance"), depicted in Fig. 2 [11, 17, 21].

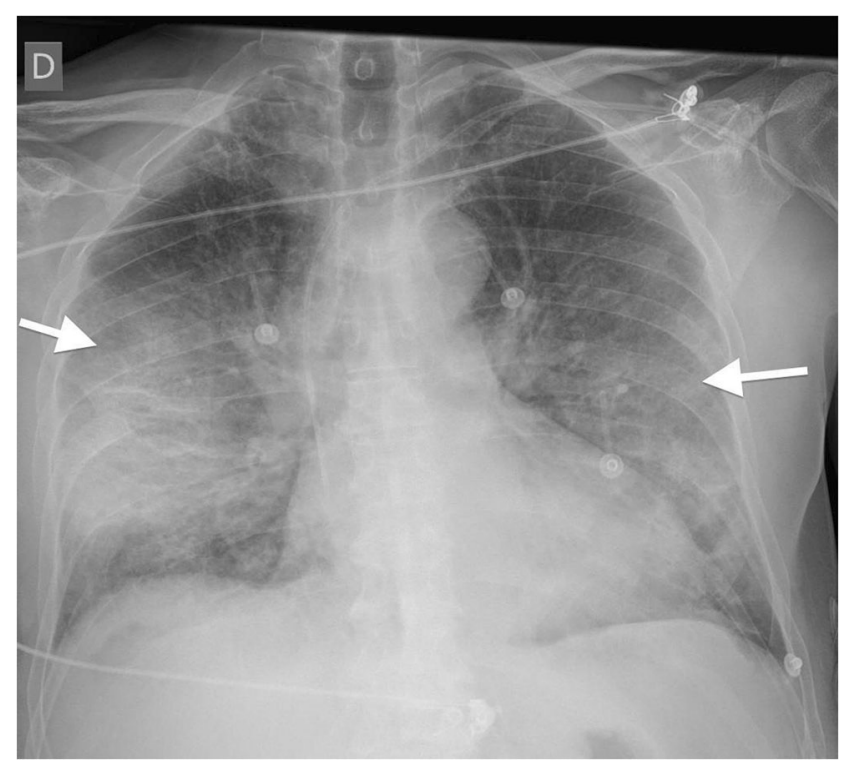

Fig. 1 Chest radiograph image from a confirmed COVID-19 case demonstrating severe pneumonia with bilateral ground-glass opacities. Note: Radiograph image from COVID-19 case (10), courtesy of Dr. Edgar Lorente, Radiopaedia.org, rID: 75187 [21]

Udugama and colleagues reported that chest CT scans were commonly used for clinical diagnosis of suspected COVID-19 cases in China initially, due to high false-negative rates of molecular testing kits and shortages [1]. However, this practice can overwhelm and place a huge burden on radiology departments during an ongoing pandemic. Additionally, imaging findings of COVID-19 reported to date are nonspecific

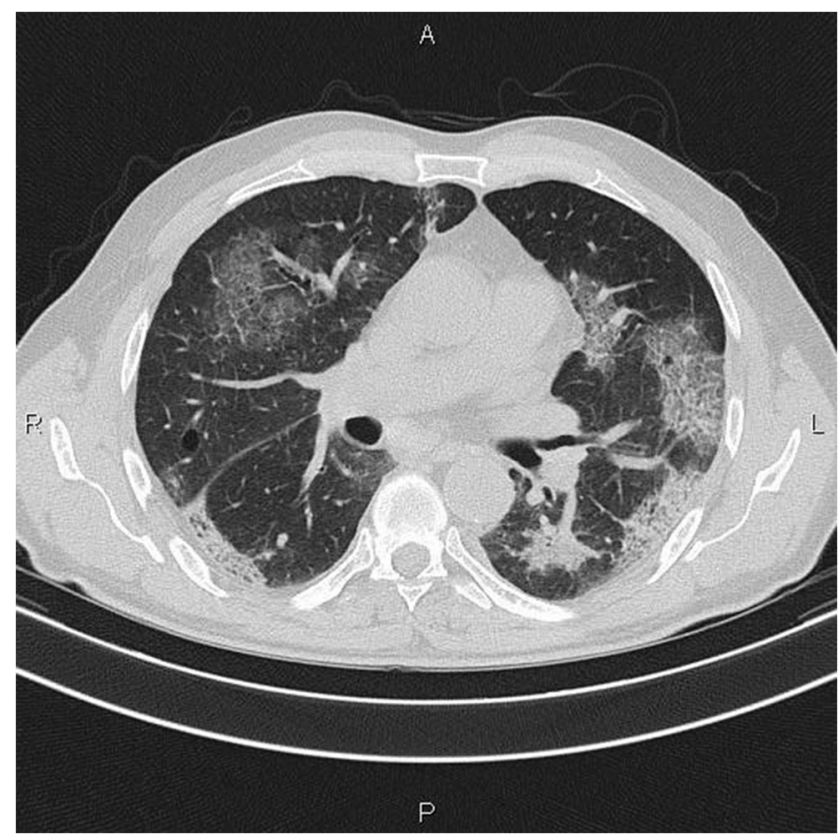

Fig. 2 CT image from a confirmed COVID-19 case showing multiple patchy and light consolidations in both lungs and grid-like thickness of interlobular septae. Note: Radiograph image of confirmed COVID-19 case (36), courtesy of Dr. Mohammad Taghi Niknejad, Radiopaedia. org, rID: 75607 [21] 
and diverse and can vary depending on disease severity, age, and underlying diseases; it can also overlap with other disease processes [1]. It also poses a risk of cross-infection, as thorough decontamination is required after scans of suspected or confirmed COVID-19 cases [1]. If imaging is needed, due to the ease of decontamination and infection control, portable chest X-ray (CXR) should be considered in suspected COVID-19 cases [14]. The American College of Radiology (ACR) in the USA currently recommends against using CT scanning for screening or diagnosis of COVID-19, except when needed for assessment of disease severity and management $[11,14]$.

\section{Lung Ultrasonography}

As new cases of COVID-19 overwhelm healthcare systems, countries, and regions are examining various complementary diagnostic approaches, including lung ultrasound (LUS) [19]. Dondorp and Schultz suggest deployment of point-of-care LUS as an alternative for chest X-ray and CT scan in suspected COVID-19 pneumonia cases, particularly in settings where resources are limited and patients are financially deprived $[19,22]$. Preliminary studies, although not specific, reported LUS abnormalities including diffuse B-pattern and/ or subpleural consolidation in confirmed COVID-19 cases [22]. In one confirmed COVID-19 case, LUS abnormalities were observed by the twelfth-day of hospital admission [19]. Although some data suggest COVID-19 has a predilection for disease in subpleural regions, to date, there is limited evidence of specific LUS features to diagnose and distinguish COVID19 from other pulmonary infections [14].

\section{Laboratory Diagnosis with RT-PCR and Serology}

The designation of "pneumonia of unknown etiology" is given when an illness without any identifiable pathogen meets the criteria of fever $\left(\geq 38{ }^{\circ} \mathrm{C}\right)$, radiographic confirmation of pneumonia, low or normal lymphocyte count, and no symptomatic improvement after antimicrobial therapy for 3 to 5 days following standard clinical care guidelines [23]. These guidelines that were used by local hospitals to help identify the cause of sudden emergence of pneumonia cases in Wuhan, China, were set up during the 2003 SARS outbreak to enable identification of unknown pathogens [23]. On December 29, 2019, the first 4 cases of pneumonia of unknown etiology were identified and reported to share a linkage of exposure to a contact source with the Huanan Seafood Wholesale Market [23]. An epidemiologic alert was released by the local health authority on December 31,2019, and the market eventually closed on January 1,2020, as the number of suspected cases increased [4]. To date, there is considerable dispute and uncertainty over the origin of the novel virus as further investigations of the earliest confirmed cases reveal many had no link to the seafood market [24].

Once cases were identified to have met the criteria for pneumonia of unknown etiology, attempts were then made to increase the sensitivity for early detection by confirming whether or not the patient had any contact with Huanan Seafood Wholesale Market or other symptomatic patients [23]. The criteria to define a suspected case were updated again on January 18,2020 , and now took into consideration travel history to Wuhan or any direct contact with symptomatic patients within 14 days before the onset of their illness [23]. A recent study conducted by Li Q. and colleagues [23] looked at the first 425 laboratory-confirmed cases to further distinguish the characteristics and transmission properties of the pathogen. A confirmed case was defined when respiratory samples tested positive for 2019 novel coronavirus (2019$\mathrm{nCoV}$ ) by isolation, two positive results by real-time RTPCR assay, or genetic sequence that matched 2019-nCoV [23]. The RNA that was obtained from the upper and lower respiratory tract of patients were tested by real-time RT-PCR, if the two targets tested positive, the case would be considered laboratory-confirmed [23]. A cycle threshold value (Ct value) of less than 37 was determined to be a positive test and a $\mathrm{Ct}$ value of 40 or more was deemed to be a negative test. If the $\mathrm{Ct}$ value fell between 37 and 40, then it was required to undergo repeated testing; if the repeated $\mathrm{Ct}$ value was less than 37 or if it was less than 40 with a clear peak being recorded, then the retest would be regarded as positive [23].

The use of real-time RT-PCR is highly suggested for confirming a suspected case, as well as for detecting the presence of pathogens by way of 2019-nCoV nucleic acid detection in samples from the patient's respiratory tract or blood [25]. Real-time RT-PCR is regarded as an important diagnostic tool in providing accurate RNA detection of 2019-nCoV as gene-specific primers target various viral protein genes, such as the envelope protein gene or the nucleocapsid protein gene. Both have proven to be sensitive and specific toward the SARS-CoV-2 virus and have helped rule out other types of coronaviruses and possible related viruses [26, 27]. In a cohort study of 205 confirmed COVID-19 cases, a collection of 1070 various tissue specimens, including blood, sputum, feces, urine, nasal, BAL fluid, and fibro-bronchoscopy brush biopsy tested for viral RNA through real-time RT-PCR, revealed detection of SAR-CoV-2 from multiple sites. However, samples from the BAL fluid displayed the highest rates of RT-PCR positivity (93\%) and a 95\% confidence interval (28.9-33.2) [28]. Woloshin and colleague's preliminary studies report estimated the sensitivity for various available RT-PCR tests to be $70 \%$ [29].

Unfortunately, a negative PCR test on its own still cannot rule out the possibility of infection. As local authorities would go on to report cases where despite the patients' initial realtime RT-PCR test proving to be negative, they would 
demonstrate chest CT scans with various degrees of consolidation and ground-glass opacity $[20,26]$. This could also explain the initial proposals of pneumonia of unknown origins during the early days of the outbreak as those patients' CT scans revealed different levels of thick, abundant opacities alongside negative results of the initial PCR test [1]. These patients would eventually prove to be positive during their second or third round of testing [26], indicating a need for diagnostics such as radiology to be complementary to realtime RT-PCR.

Newer serological rapid diagnostic tests are being developed with the hopes of being complementary to current diagnostics and more specific in its approach. In Zhongnan Hospital of Wuhan University, serological detection methods using a colloidal gold-based immunochromatographic (ICG) strip which targets viral IgM and IgG antibodies, are currently being used [26]. Despite RT-PCR being accepted as the standard diagnostic method of SARS-CoV-2 in China and worldwide, there is still an increasing rate of false-negative cases from local authorities [29]. In a study conducted by Pan and colleagues, data was obtained by collecting 86 samples from 67 RT-PCR confirmed SARS-CoV-2 positive patients in an attempt to compare the ICG strip with RT-PCR [26]. The disease duration was divided into 3 stages, the early stage (1 to 7 days from onset), the intermediate stage (8 to 14 days), and the late stage (more than 15 days), with the positive rates of IgM and IgG starting lower and progressively increasing as the disease advances [26]. The sensitivity of ICG assays increased and is estimated to peak at 15 days. It is also acceptable to combine both IgM and IgG parameters to increase the positive rate and sensitivity [26]. Total antibodies are serological markers that can be increased by the second week of symptom onset and are considered to be very sensitive [30].

Comparable with older studies of immunoglobulins against SARS-CoV indicated that IgM and IgG antibodies were detectable after 7 days. COVID-19 patients also demonstrated that both IgM and IgG can be detected after 5 days of onset by an anti-SARS-CoV-2 enzyme-linked immunosorbent assay (ELISA) [26]. In other words, ELISA was deemed quantitative, whereas the ICG strip provided qualitative results [26]. ELISA-based IgM and IgG antibody tests have shown greater than $95 \%$ specificity for the diagnosis of COVID-19, as antibodies are produced against the viral nucleocapsid (NC) and the receptor-binding domain of the spike protein (RBD-S) [30]. The nucleocapsid is a protein containing viral nucleic acid and the RBD-S is a protein used by the virus for attachment to the host cell; these antigens can be used individually or together to detect IgM and IgG antibodies, as well as increase overall sensitivity [30].

Furthermore, researchers using a single-lane rapid $\mathrm{IgG} /$ IgM lateral flow assay directed to the nucleocapsid protein of SARS-CoV-2 have identified that the sensitivity and specificity for IgG were $92.2 \%$ and $97.0 \%$ [31]. However, the sensitivity and specificity for IgM were only $57.9 \%$ and 91.3\% respectively [31]. The development of newer serological assays for SARS-CoV-2 could help improve current methods of screening the population, so it is recommended they undergo an assessment for their performance and capabilities using clinical specimens [32]. A recent study by Jääskeläinen and colleagues assessed the specificity and sensitivity of 6 commercial immunoassays for the detection of SARS-CoV-2 antibodies and then compared it with neutralization assays, which are the gold standard for specificity and can indicate if there has been any development of immunity; their results showed variable performance values for the immunoassays [32].

The current WHO recommendations are to use these new point-of-care immunodiagnostic serology tests in a research setting only and are advised against using them in clinical decision-making setting [33]. These simple test kits with a sensitivity range of 34 to $80 \%$ are based either on protein detection from the COVID-19 virus in respiratory samples such as sputum, throat swab, or detection, in blood or serum, of human antibodies generated in response to infection [33]. The performance of these tests depends on several factors, including the time from onset of illness, the concentration of virus in the specimen, the quality of the specimen collected from a person and how it is processed, and the precise formulation of the reagents in the test kits [33].

Antibodies against the virus are produced over days to weeks after infection; the majority of patients develop antibody response only in the second week after onset of symptoms. Hence, a diagnosis of COVID-19 infection based on antibody response will often only be possible in the recovery phase, when many of the opportunities for clinical intervention or interruption of disease transmission have already passed. Also, the antibody test is limited by cross-reaction with other pathogens, including other human coronaviruses, thus giving false-positive results [17, 33].

Upper respiratory tract samples used for diagnosis include nasopharyngeal swabs, oropharyngeal swabs, nasopharyngeal washes, and nasal aspirates. Lower respiratory tract samples include sputum, BAL fluid, and tracheal aspirates. It should be noted that obtaining both BAL and tracheal aspirates can be high-risk due to an aerosol generation which would increase the risk of person-to-person transmission [1]. The analysis of patients' BAL fluid led to the discovery that the pathogen has a similar genetic sequence with the betacoronavirus B lineage. Through BAL fluid, it was also revealed that the SARS-CoV2 virus genome has $80 \%$ similarity with the SARS-CoV genome, $50 \%$ similarity with the Middle East respiratory syndrome virus (MERS-CoV) genome, and a $96 \%$ similarity with the bat coronavirus RaTG13 genome [1]. Further studies indicated that the coronavirus' RNA genome contains various structural proteins that assist in its growth. The spike (S) protein binds to a receptor and fuses with the host membrane, the 
membrane (M) protein is involved in viral assembly and the nucleocapsid (N) protein binds with the RNA genome to form the nucleocapsid which helps regulate viral RNA synthesis [34]. The entry receptor for SARS-CoV was identified by mass spectrometry to be ACE2, an enzyme related to angiotensin-converting enzyme (ACE), with the virus entering the host cell when the (S) protein bound to ACE2 [35]. Similarly, the new SARS-CoV-2 also binds to the same receptor for viral entry, ACE2.

By January 31, 2020, the epidemic had been reported to have already spread to 19 countries with 11,791 confirmed cases, including 213 deaths [3], resulting in the WHO declaring COVID-19 an official Public Health Emergency of International Concern. As of April 2, 2020, the disease had spread to at least 202 countries, infected over 1 million people, and was adjudged to have resulted in 45,526 deaths globally [1]. In dismay and now affecting 213 countries and territories, the number of cases has surpassed eight million with over 400,000 fatalities, as of June 19, 2020 [7]. Therefore, the use of diagnostic testing on a large scale to identify those infected with the SARS-CoV-2 infection has been recognized by many countries as a necessary tool to help combat this global pandemic COVID-19 [17].

\section{Conclusion}

A global initiative to accelerate the development, production, and equitable access to diagnostics has become a main priority for the COVID-19 pandemic. Diagnostics provide crucial data that leveraged to make critical patient care decisions; it also aids in reducing the spread of the virus through increased early detection, which ultimately decreases mortality. However, COVID-19's limited data set engenders a learning curve regarding its diagnosis. Molecular testing remains the gold standard for diagnosing COVID-19, and it should be the first test of choice for the diagnosis of acute COVID-19 infection. It represents the most accurate test methodologies for the detection of the SARS-CoV-2 virus gene sequences during the early stage of infection. Unfortunately, processing patient samples with RT-PCR may take hours-to-days, coupled with the shortage of testing capacity and reagents for COVID-19. For example, a one-step multiplex 2019-nCoV qRT-PCR assay typically takes 1 hour after RNA extraction and can test hundreds of samples per run, hence the need for radiology diagnosis to be complementary to RT-PCR for diagnosing severe COVID-19. Also, many rapid diagnostic tests have been developed that utilize the detection of proteins from the COVID-19 virus in respiratory samples or detection, in blood or serum, of human antibodies generated in response to infection. Each test type has advantages and disadvantages inherent to its underlying technology; thus, pivoting test types and timings may be useful tools for managing the pandemic. The
COVID-19 outbreak has demonstrated the necessity of a system that facilitates the rapid development and implementation of diagnostic tests against infectious diseases. Exemplary tests should be rapid and inexpensive; it could come with simple smartphone integration capabilities that can be shipped to patients' homes. Home-based point -of- care testing allows the patients to screen themselves in-home and share the test results with healthcare workers without visiting the hospital. Adopting this test could potentially be used as triage in healthcare settings to rapidly identify patients who are very likely to have COVID-19, thus reducing or eliminating the need for expensive molecular confirmatory testing, and also eliminating potential exposure to front-line healthcare workers due to delayed testing. Since the virus is highly contagious and has the potential to cause a variety of symptoms, identifying infected individuals not only helps to provide appropriate medical treatment but also significantly decreases the potential for transmission. Hence, a combination of the disease history, clinical manifestations, laboratory diagnostic testing, and diagnostic imaging is crucial for making an accurate and useful diagnosis for COVID-19.

\section{Compliance with Ethical Standards}

Conflict of Interest The authors declare that they have no conflict of interest.

\section{References}

1. Udugama B, Kadhiresan P, Kozlowski HN, Malekjahani A, Osborne M, Li VYC, et al. Diagnosing COVID-19: the disease and tools for detection. ACS Nano. 2020. [Accessed April 20, 2020;30:3822-35. https://doi.org/10.1021/acsnano.0c02624.

2. Marchand-Senécal X, Kozak R, Mubareka S, Salt N, Gubbay JB, Eshaghi A, et al. Diagnosis and management of first case of COVID-19 in Canada: lessons applied from SARS. Clin Infect Dis. 2020;9. https://doi.org/10.1093/cid/ciaa227. [Accessed April 20, 2020, https://doi.org/10.1093/cid/ciaa227/5800047.

3. Adhikari SP, Meng S, Wu Y-J, Mao Y-P, Ye R-X, et al. Epidemiology, causes, clinical manifestation and diagnosis, prevention and control of coronavirus disease (COVID-19) during the early outbreak period: a scoping review. Infect Dis Poverty. 2020;9(29) Accessed April 20, 2020. https://doi.org/10.1186/ s40249-020-00646-X.

4. Wu Y-C, Chen C-S, Chan Y-J. The outbreak of COVID-19. J Chin Med Assoc. 2020;83(3):217-20. https://doi.org/10.1097/jcma. 0000000000000270 Accessed April 20, 2020, https://journals. lww.com/jcma/FullText/2020/03000/The_outbreak_of_COVID 19_An_overview.3.aspx.

5. van Doremalen N, Bushmaker T, Morris DH, Holbrook MG, Gamble A, Williamson BN, et al. Aerosol and surface stability of SARS-CoV-2 as compared with SARS-CoV-1. N Engl J Med. 2020;382:1564-7. [Accessed April 20, 2020. https://doi.org/10. 1056/NEJMc2004973.

6. Li X, Geng M, Peng Y, Meng L, Lu S. Molecular immune pathogenesis and diagnosis of COVID-19. J Pharm Anal. 2020;5:102-8. https://doi.org/10.1016/j.jpha.2020.03.001. [Accessed April 20, 
2020, https://www.sciencedirect.com/science/article/pii/ S2095177920302045.

7. WHO. Coronavirus disease 2019 (COVID-19): Situation report 151. World Health Organization. June 19, 2020. [Accessed June 19, 2020, https://www.who.int/docs/default-source/ coronaviruse/situation-reports/20200619-covid-19-sitrep151.pdf?sfvrsn=8b23b56e_2].

8. Cowling BJ, Aiello AE. Public health measures to slow community spread of coronavirus disease. J Infect Dis. 2019;20:2020. https:// doi.org/10.1093/infdis/jiaa123 Accessed April 20, 2020, 10.1093/ infdis/jiaa123/5810274.

9. Wang D, Hu B, Hu C, Zhu F, Liu X, Zhang J, et al. Clinical characteristics of 138 hospitalized patients with 2019 novel coronavirus-infected pneumonia in Wuhan, China. JAMA. 2020;323(11):1061-9 Accessed April 20, 2020, https:// jamanetwork.com/journals/jama/fullarticle/2761044.

10. WHO. Clinical management of severe acute respiratory infection when COVID-19 is suspected. World Health Organization. 2020. [Accessed April 20, 2020]https:/www.who.int/publications-detail/ clinical-management-of-severe-acute-respiratory-infection-whennovel-coronavirus-(ncov)-infection-is-suspected].

11. CDC. Interim clinical guidance for management of patients with confirmed coronavirus disease (COVID-19). Centers for Disease Control and Prevention. April 23, 2020. [Accessed April 24, 2020, https://www.cdc.gov/coronavirus/2019-ncov/hcp/clinicalguidance-management-patients.html\#clinical-course].

12. WHO. Report of the WHO-China Joint Mission on coronavirus disease 2019 (COVID-19). World Health Organization. February 28, 2020. [Accessed April 24, 2020] https://www.who.int/docs/default-source/coronaviruse/who-china-joint-mission-on-covid-19-final-report.pdf].

13. Yan C, Faraji F, Prajapati D, Boone C, DeConde A. Association of chemosensory dysfunction and COVID-19 in patients presenting with influenza-like symptoms. Int Forum Allergy Rhinol. 2020. [Accessed April 23, 2020]. https://doi.org/10.1002/alr.22579.

14. ACP. COVID-19: An ACP physician's guide and resources. American College of Physicians. April 24, 2020. [Accessed April 24, 2020, https://assets.acponline.org/coronavirus/scormcontent/? $\mathrm{ga}=2.229126044 .1484631089 .158376785245448268$. $1580931839 \&$ \&ac $=1.12324352 .1584127450$. E A I a I Q o b C h M I 04 D iPTk2gIVSFqGCh11lwA1EAAYASAĀEgKoB D BwE\&utm campaign=FY19-20_MD_MEDED_EML_COVID19 MD92941 MAR19\&utm medium=email\&utm source= Eloqua\#/].

15. Covid CD, Team R. Severe outcomes among patients with coronavirus disease 2019 (COVID-19) — United States, February 12March 16, 2020. MMWR Morb Mortal Wkly Rep. 2020;69(12): 343-6.

16. Petrilli CM, Jones SA, Yang J, Rajagopalan H, O'Donnell LF, et al. Factors associated with hospitalization and critical illness among 4, 103 patients with COVID-19 disease in New York City. medRxiv. 2020. [Accessed April 24, 2020. https://doi.org/10.1101/2020.04. 08.20057794.

17. Cheng M, Papenburg J, Desjardins M, Kanjilal S, Quach C, et al. Diagnostic testing for severe acute respiratory syndrome-related coronavirus-2: a narrative review. Ann Intern Med. 2020;13:72634. https://doi.org/10.7326/M20-1301. [Accessed April 24, 2020, 10.7326/M20-1301.searchresult=1\&.

18. Zheng Y-Y, Ma Y-T, Zhang J-Y, Xie X. COVID-19, and the cardiovascular system. Nat Rev Cardiol. 2020, 2020. https://doi.org/ 10.1038/s41569-020-0360-5. [Accessed April 21, 2020, https:// www.nature.com/articles/s41569-020-0360-5\#citeas.

19. Dondorp A, Schultz M. Early lessons on the importance of lung imaging in novel coronavirus disease (COVID-19). Am J Trop Med
Hyg. 2020. [Accessed April 24, 2020. https://doi.org/10.4269/ ajtmh.20-0225.

20. Bilal M, Shahzad MU, Han J, et al. Positive Chest CT and Negative RT-PCR Testing in a Case of Suspected COVID-19. Clin Case Rep Open Access. 2020;3(2):144.

21. Skandhan AKP, Bell DJ. COVID-19. Radiopaedia. 2020; Accessed April 24, 2020, https://radiopaedia.org/articles/covid-193?lang=us.

22. Poggiali E, Dacrema A, Bastoni D, Tinelli V, Demichele E, et al. Can lung US help critical care clinicians in the early diagnosis of novel coronavirus (COVID-19) pneumonia? Radiology. 2020. [Accessed April 24, 2020. https://doi.org/10.1148/radiol. 2020200847.

23. Li Q, Guan X, Wu P, Wang X, Zhou L, Tong Y, et al. Early transmission dynamics in Wuhan, China, of novel coronavirusinfected pneumonia. N Engl J Med. 2020;382:1199-207. https:// doi.org/10.1056/NEJMoa2001316 Accessed April 24, 2020, https://www.nejm.org/doi/full/10.1056/NEJMoa2001316.

24. Cohen J. Wuhan seafood market may not be source of novel virus spreading globally. Science. 2020;26. https://doi.org/10.1126/ science.abb0611 Accessed June 16, 2020, https://www. sciencemag.org/news/2020/01/wuhan-seafood-market-may-notbe-source-novel-virus-spreading-globally.

25. Jin Y-H, Cai L, Cheng Z, Cheng H, Deng T, et al. A rapid advice guideline for the diagnosis and treatment of 2019 novel coronavirus (2019-nCoV) infected pneumonia (standard version). Mil Med Res. 2020;7(4). https://doi.org/10.1186/s40779-020-0233-6 Accessed April 22, 2020, https://mmrjournal.biomedcentral.com/articles/10. 1186/s40779-020-0233-6\#citeas.

26. Pan Y, Lia X, Yang G, Fan J, Tang Y, et al. Serological immunochromatographic approach in diagnosis with SARS-CoV2 infected COVID-19 patients. J Inf Secur. 2020. https://doi.org/10. 1016/j.jinf.2020.03.051 Accessed April 23, 2020. https://www. journalofinfection.com/article/S0163-4453(20)30175-4/fulltext.

27. Pathak M, Kumar Patel S, Rana J, Tiwari R, Dhama K, Sah R, et al. Global threat of SARS-CoV-2/COVID-19 and the need for more and better diagnostic tools. Arch Med Res. 2020;51(5):450-2. https://doi.org/10.1016/j.arcmed.2020.04.003 Accessed April 23, 2020, https://www.sciencedirect.com/science/article/pii/ S0188440920304604?via\%3Dihub.

28. Wang W, Xu Y, Gao R, Lu R, Han K, et al. Detection of SARSCoV-2 in different types of clinical specimens. JAMA. 2020;323(18):1843-4. https://doi.org/10.1001/jama.2020.3786 Accessed June 15, 2020, https://jamanetwork.com/journals/jama/ fullarticle/2762997.

29. Woloshin S, Patel N, Kesselheim AS. False-negative tests for SARS-CoV-2 infection - challenges and implications. N Engl J Med. 2020;5. https://doi.org/10.1056/nejmp2015897 Accessed June 16, 2020, https://www.nejm.org/doi/full/10.1056/ NEJMp2015897.

30. Sethuraman N, Jeremiah SS, Ryo A. Interpreting diagnostic tests for SARS-CoV-2. JAMA. 2020;323(22):2249-51. https://doi.org/ 10.1001/jama.2020.8259 Accessed June 15, 2020, https:// jamanetwork.com/journals/jama/fullarticle/2765837.

31. Steensels D, Oris E, Coninx L, Nuyens D, Delforge M-L, Vermeersch P, et al. Hospital-wide SARS-CoV-2 antibody screening in 3056 staff in a tertiary center in Belgium. JAMA. 2020;15. https://doi.org/10.1001/jama.2020.11160 Accessed June 19, 2020, https://pubmed.ncbi.nlm.nih.gov/32539107/.

32. Jääskeläinen AJ, Kuivanen S, Kekäläinen E, Ahava MJ, Loginov $\mathrm{R}$, et al. Performance of six SARS-CoV-2 immunoassays in comparison with microneutralisation. medRxiv, DOI. 2020. https://doi. org/10.1101/2020.05.18.20101618 Accessed June 15, 2020 https:// www.medrxiv.org/content/10.1101/2020.05.18.20101618v1.

33. WHO. Advice on the use of point-of-care immunodiagnostic tests for COVID-19. World Health Organization. 2020. https:// 
www.who.int/news-room/commentaries/detail/advice-on-the-useof-point-of-care-immunodiagnostic-tests-for-covid-19]. Accessed 21 Apr 2020

34. McIntosh K, Hirsch MS, Bloom A. Coronavirus disease 2019 (COVID-19). UpToDate Hirsch MS Bloom. 2020;5. http://drhmd. ir/wpcontent/uploads/2020/04/2_5208516520715486683.pdf

35. Turner AJ, Hiscox JA, Hooper NM. ACE2: From vasopeptidase to SARS virus receptor. Res Focus. 2004;25(6):P291-4. https://doi. org/10.1016/j.tips.2004.04.001 Accessed April 24, 2020. https://
www.cell.com/trends/pharmacological-sciences/fulltext/S01656147(04)00097-5?_returnURL=https\%3A\%2F\%2Flinkinghub. elsevier.com\%2Fretrieve\%2Fpii\%2FS0165614704000975\% 3 Fshowall $\% 3$ Dtrue\#articleInformation].

Publisher's Note Springer Nature remains neutral with regard to jurisdictional claims in published maps and institutional affiliations. 